\title{
Alexandre Herculano e as obras da Colegiada de Guimarães
}

\author{
maria Helena T. Maia *
}

\begin{abstract}
RESUMO
ABSTRACT

Tomando como exemplo as críticas de

Taking as an exemple, Alexandre

Alexandre Herculano às obras Herculano's criticism on the repair efectuadas na igreja de Nossa Senhora da Oliveira, vulgarmente referida como Colegiada de Guimarães, este trabalho procura analisar alguns dos pressupostos do discurso sobre o património e o restauro arquitectónicos corrente nos textos da imprensa romântica portuguesa da primeira metade do século xix e a sua articulação com o contexto cultural para que remetem. work done on the church of Nossa Senhora da Oliveira, usually refered to as the Colegiada de Guimarães, this work attempts to analise some of the pressuppositions of the discourse on architectural heritage and restauration in romantic portuguese press articles during the first half of the Xixth century and their relationship with the cultural context they refer to.
\end{abstract}

A figura e a obra de Alexandre Herculano constituem simultaneamente um marco para a compreensão dos termos em que se estrutura a consciência patrimonial portuguesa da primeira metade de oitocentos e o seu exemplo mais imediatamente paradigmático.

Sem se pretender, neste curto trabalho, abordar o processo e a obra em toda a sua complexidade, pensa-se no entanto, que merecerá a pena tentar

* Professora da Escola Superior Artística do Porto (ESAP) e investigadora do Centro de Estudos Arnaldo Araújo da mesma instituiçāo. 
delimitar, a partir das referências do autor à Colegiada de Nossa Senhora da Oliveira, em Guimarães, algumas das linhas gerais do seu pensamento no que respeita à defesa do património, pensamento que aqui se cruza com alguns dos pressupostos inerentes à ideia de restauro corrente nos textos da época '.

A escolha do autor dispensa explicações, a sua importância no contexto cultural português é por demais conhecida e foi já e melhor abordada.

A escolha da obra, decorre da muito especial atenção que Herculano Ihe dedicou, usando-a como exemplo recorrente ${ }^{2}$ de destruição/descaracterização do património edificado o que, acaba por permitir objectivar, a partir das observações que the são destinadas, algumas das linhas gerais do seu pensamento sobre o tema.

Mas, o estudo das reflexões de Alexandre Herculano sobre as obras realizadas na Colegiada de Nossa Senhora da Oliveira permite ainda, segundo penso, exemplificar modelarmente os pressupostos ideológicos que, no campo da relação com o património edificado, informam a grande maioria dos textos publicados na imprensa da época, e a distância que neste campo os separa daqueles que parecem ser partilhados pela grande maioria da população.

$\mathrm{Na}$ verdade, a progressiva definição da consciência patrimonial face ao edificado não foi, nem poderia ser, um processo homogéneo ou homogeneamente evolutivo.

Em Portugal e à semelhança do que, segundo Diane Barthel, aconteceu com a Grã Bretanha, "as classes mais altas dominaram historicamente o Projecto de Preservaçāo e continuam a fazê-lo" ${ }^{3}$, entendendo-se por projecto de preservação uuma tentativa de revalorizar e re-presentar o passado através da salvaguarda, manutenção e/ou reconstrução de estruturas e artefactos históricos e através do crescente reconhecimento público da sua identificação com a história local, regional e/ou nacional’" ${ }^{4}$.

Sobre a evolução das noçōes de património e restauro arquitectónicos em Portugal. até 1880, ver MAIA, Maria Helena Teixeira: O Restauro Arquitectónico em Portugal. Emergência e consolidaçāo de uma noção. Tese de Doutoramento. Universidad de Valladolid, 2001, trabalho em que se baseia o presente artigo.

Para esta recorrência toi já chamada a atençāo por José-Augusto França ("A Arte Medieval Portuguesa na Visão de Herculano" in Alexandre Herculano à luz do nosso tempo. Lisboa: Academia Portuguesa de História, 1977).

3 No original: "the upper classes have historically dominated the Preservation Project and continue to do so" (BARTHEL, Diane: Historic Preservation. Collective memory and historical identity. New Brunswick, New Jersey: Rutgers University Press, 1996, pág. 5).

4 No original: "an attempt to revalue and re-present the past through saving, mantaining, and/or reconstructing historic structures and artifacts, and through heightening public awareness of their significance with local, regional, and/or national history" (Ibidem, pág. 2). 
A precoce institucionalização (1721) da noção de património nacional acompanhada do estabelecimento de mecanismos de tutela correspondentes ${ }^{5}$, cujo vanguardismo já se defendeu ${ }^{6}$, corresponde a uma estruturação notavelmente elaborada do "projecto de preservação" português, sobretudo se se atender à época em que foi formulado, mas que não deixou de ter que se confrontar com uma resistência e/ou uma indiferença claramente dominantes?

$\mathrm{Na}$ verdade, a consciência patrimonial necessária à existência desse "projecto de preservação" foi até ao século XVIII atributo dos meios cultos, essencialmente compostos por membros da nobreza e do alto clero -as classes mais altas de que fala Barthel- a que se vão progressivamente juntando profissionais ligados às artes e parte da pequena nobreza e do clero provinciais.

A associação daqui decorrente entre o interesse e defesa do património e o prestigio das classes que Ihe deram origem, explica em grande parte a adesão que o tema encontrará entre a burguesia ascendente do século seguinte, mas os lamentos e as denuncias correntes na imprensa da época indicam o carácter epidérmico dessa adesão sendo, mais uma vez nos meios intelectuais - agora mais heterogeneamente compostos, mas não menos elitistas no que se refere ao lugar socialmente ocupado pelos seus membros-que se terão de procurar as bases de reestruturação do "projecto de preservação" nacional.

Na realidade, a dualidade de atitudes que desde sempre acompanhou a definição do quadro patrimonial e a relação com ele estabelecida, não desapareceu no século $X \mid x$, como ainda hoje não desapareceu, pensandose que, neste campo, a evolução e a importância do "projecto de preservação" se coloca sobretudo ao nivel da clareza com que é expresso, da percentagem relativa dos grupos a ele aderentes ou não e do prestigio social que vai adquirindo.

Assim, a uniformidade relativa de atitudes face ao problema do património, que se detecta em Portugal nas décadas de 1830 e 40 , é na realidade uma uniformidade restrita à intelligenzia liberal, formada no exilio e por ele informada, que domina a cena política e detém o controle dos meios de informação.

\footnotetext{
Fixados no Alvará Régio de 20 de Agosto de 1721.

6 MalA, M. Helena: "Património e Restauro no Século xVIIl Português. 1721-1802", Cadernos ESAP, 2\&3, 1987, pág. 103

lbidem, pág. 105.
} 


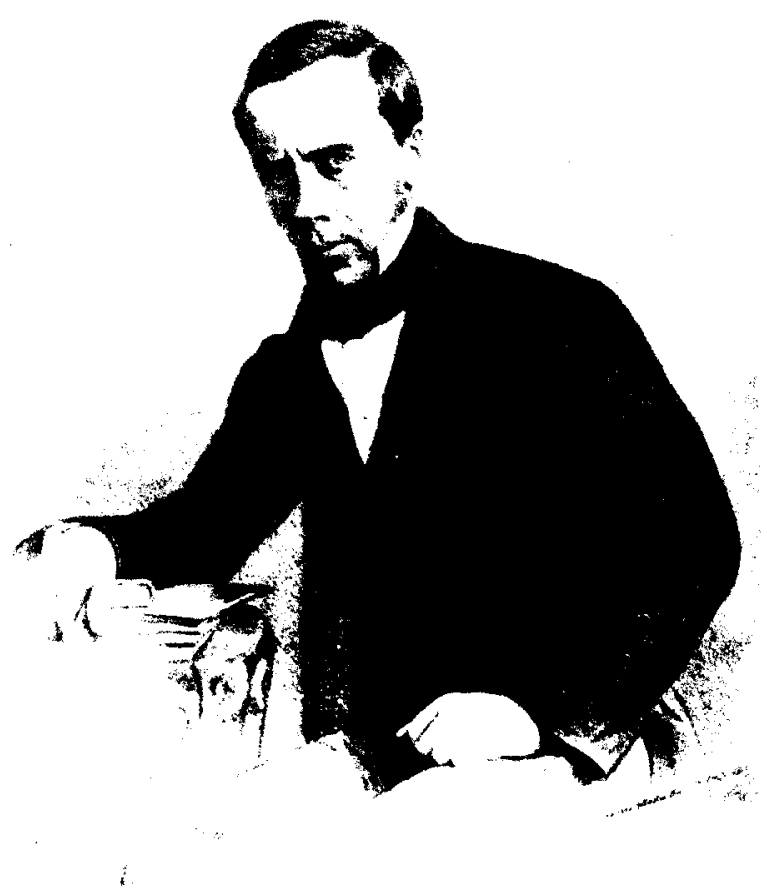

Fig. 1. Alexandre Herculano em 1856. Litografia da época.

De facto, a experiência do exílio inglês e sobretudo francês, contribuiu decisivamente para o reenquadramento da relação com o património em geral, fornecendo modelos e referências que se procuram adaptar, mas contribuindo também para em parte esquecer a tradição nacional.

Alexandre Herculano (Fig. 1) a quem, sem dúvida, se deve a primeira tentativa consistente de formulação teórica do problema, segue de perto nessa formulação o modelo francês, recuperando ideias e expressões dos textos de Victor Hugo e, sobretudo, de Montalembert embora no fascínio dessa aproximação ignore a história nacional ao reivindicar uma lei que Portugal já tinha há muito, mas que aparentemente fora esquecida por todos pois, neste período, apenas José Feliciano de Castilho ${ }^{8}$ a parece recordar.

8 Cf. CAStILHO, José Feliciano de: Relatório acerca da Bibliotheca Nacional e mais estabelecimentos anexos (...). Lisboa: Typ. Lusitana, 1844. Note-se porém, que Castilho era à data Biblio- 
Na mesma linha, clama-se contra a degradação do património nacional, clamor com justificações bem objectivas de existência, atendendo ao estado de ruína e abandono em que se encontravam os chamados Bens Nacionais.

Estes, constituiam uma pesada herança das sucessivas incorporaçōes nos "Próprios da Fazenda» do património das principais corporações de "mão-morta", processo que dotou o Estado liberal de um enorme conjunto de bens móveis e imóveis nos quais se incluía uma elevada percentagem daquele que é hoje considerado o património nacional.

Entre os esforços de inventariação e preservação, muitas vezes desconexos e contraditórios entre si mas também em muitos casos notáveis, e os interesses económicos da nova classe dominante, o país oferecia uma imagem geral de ruína entranhada ao longo de décadas de guerra e pilhagem que vieram juntar à penúria de muitos dos conventos o abandono dos monges.

Oferecendo condições apeteciveis para muitas instituições, as construções conventuais foram sendo maciçamente adaptadas a hospitais, quartéis, e serviços públicos, quando não passavam para as mãos de particulares.

Outras, abandonadas, caíam em ruínas ou eram desmontadas para aproveitamento da pedra ou qualquer outro uso considerado desejável no momento.

Em qualquer dos casos o à vontade com que se efectuavam as intervençōes era quase sempre total.

É neste contexto que se enquadram os "brados" e as críticas correntes na imprensa à destruição desse património edificado e aos seus autores que Herculano, mais uma vez na esteira dos seus congéneres franceses, classifica em dois tipos: os "arrasadores" e os "reformadores" " ${ }^{9}$, entre os quais repartia "com justiça, segundo nos parece, a porção de honraria que tocava a cada uma destas castas de vândalos» ${ }^{10}$.

tecário-Mor e que, enquanto tal, a lei the dizia directamente respeito na medida em que depois da sua reedição no Alvará Régio de 1802 cabia em grande parte ao ocupante deste cargo a responsabilidade da tutela do património nacional.

Montalembert, que constitui referência bem presente em Herculano, apontara já a existência de dois tipos de actuaçāo que, segundo ele, divergindo nos motivos convergiam nos resultados igualmente desastrosos para os monumentos e que designou por "vandalisme destructor" e "vandalisme restaurateur". Cf. REAU, Louis: Histoire du Vandalisme. Les monuments détruits de l'art français. Paris: Robert Laffont, 1994, pág. 694.

10 Herculano, Alexandre: "Os Monumentos II" in Opúsculos. vol. I. Lisboa: Presença, 1982.

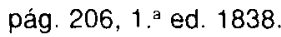


A referência à distinçāo entre "vandalismo destrutor» e "vandalismo restaurador" de Montalembert é aqui imediata, mas a substituição do "restaurador" pelo "reformador" mais do que uma adaptação terminológica corresponde ao apontamento de uma realidade muito distinta no caso da intervenção nos monumentos.

Na verdade, a condenação da adulteração da imagem primeira do edifício é unânime nos textos da época, se bem que, ao que parece com poucos efeitos na prática corrente, mas não se trata de uma adulteração resultante de uma acção de restauro entendida enquanto tal, como acontecia em Inglaterra ou em França, mas sobretudo de obras de adaptação a novas funções, efectuadas de forma desregulada e pouco atenta ao eventual valor patrimonial dos mesmos.

$\mathrm{Na}$ ausência de um inventário credivel ou minimamente eficaz, a intervenção ficava ao critério dos seus responsáveis directos que, na maioria dos casos não partilhavam, ou não estavam naquele caso interessados em partilhar, a mesma sensibilidade patrimonial em relação ao edifício em causa, nele agindo ao sabor das conveniências de momento.

Por outro lado, em muitos casos a nova função atribuída ao edifício levava pela sua manifesta inadequação à necessária adulteração do mesmo, facto de que existia perfeita consciência, sendo um dos aspectos mais frequentemente apontados como causa de destruição activa dos monumentos: "buscai os mais veneráveis edifícios: ou jazem por terra, ou foram destinados a estabelecimentos que de necessidade os estragaram» ${ }^{11}$.

Não era portanto o restauro enquanto tal que Herculano e os seus congéneres criticavam, mas sim a completa liberdade das intervenções que não levavam em consideração o valor patrimonial do monumento, fazendo-o perder 0 aspecto de "veneranda antiguidade" ${ }^{12} \mathrm{e}$ adulterando $\mathrm{o}$ seu "desenho primitivo" ${ }^{13}$ características que, segundo acreditavam, importava acima de tudo conservar.

Por outro lado, as metamorfoses sofridas pelos monumentos ao longo da sua existência surgiam como monstruosas adulterações, independentemente do valor histórico e/ou documental que pudessem eventualmente ter, ao mesmo tempo que a frágil cultura arquitectónica dos autores das

lbidem, pág. 195.

Ibidem, pág. 208.

Herculano, Alexandre: Apontamentos de Viagem. Apud Franç, José-Augusto: Op. cit., pág. 64 . 


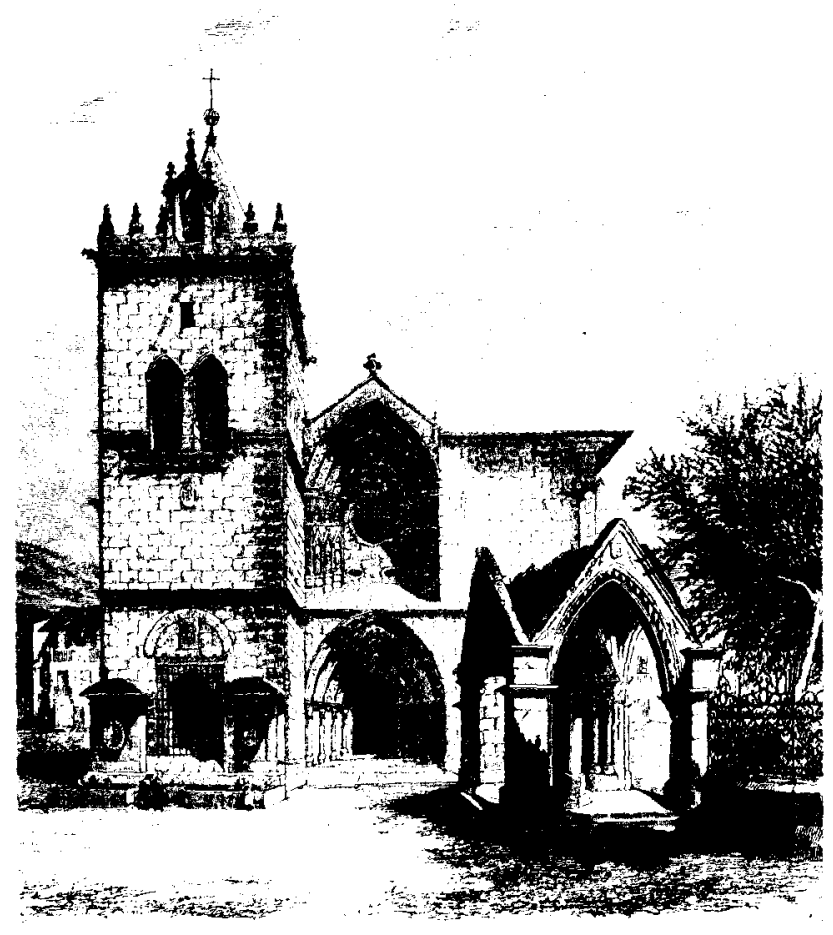

Fig. 2. Colegiada de Guimarães. Gravura publicada no Archivo Pittoresco, T. VI, n." 45 . 1961, associada ao artigo de Vilhena Barbosa.

críticas ${ }^{14}$, de que Herculano é um bom exemplo, leva a que a condenação de alguns dos aspectos mais epidérmicos dessas metamorfoses seja sobrevalorizada em detrimento de transformações mais profundas que, em muitos casos, thes passam despercebidas.

A análise das críticas de Alexandre Herculano às obras da Colegiada de Nossa Senhora da Oliveira (Fig. 2) poderá talvez ajudar a compreender e melhor objectivar o que se tem vindo a defender.

14 Em Portugal e mais uma vez à semelhança do que acontecera em Inglaterra e França, será a partir dos meios literários que se estruturará o movimento de defesa do património que, nāo Ihes sendo exciusivamente circunscrito, é através deles que adquire maior visibilidade. Vd. MAIA, M. Helena: O Restauro... 
Logo no primeiro texto que dedica aos monumentos, o autor escolhe-a, de entre os inúmeros exemplos possiveis de intervençāo destrutiva, informando: "À hora em que isto escrevemos soam talvez as pancadas dos martelos na antiga Colegiada de Guimarães, onde se vão gastando largas somas, para destruir em parte, em parte tornar monstruosa, uma das mais formosas obras da arquitectura nacional»" ${ }^{15}$.

$\mathrm{Na}$ Colegiada, que considera "um dos mais belos monumentos da arquitectura gótica» 16 -obra "grandiosa", se bem que «menos importante» que a da Batalha ${ }^{17}$ - . Herculano valoriza a proporção dos arcos, a decoração "variada e subtil»" ${ }^{18}$ dos capiteis, as naves e os pilares que adjectiva respectivamente de "majestosas" e «formosos", e o sentimento de “respeito saudoso, que só sabem produzir as igrejas góticas" ${ }^{19}$.

Nesta descrição exemplar se resume a abordagem que da arquitectura fazia o autor.

Os elementos constituintes do edifício são enumerados e adjectivados, podendo incluir-se nessa enumeração a utilização do conceito de "proporção", único que poderia remeter para uma abordagem de outro tipo. $O$ edifício é descrito como um somatório de partes, se bem que se reconheça ao conjunto em si valores expressivos, comummente atribuídos ao estilo e que remetem para um certo entendimento espacial, derivado da identificação do efeito que produz ao nivel da sensibilidade.

De índole semelhante é a descrição dos crimes de "lesa-arte, lesa-gosto, e lesa-razão" que os cónegos aí estavam cometendo, em que o autor reproduz a crítica mais corrente a este género de intervenções: destruição da decoração dos capiteis e cornijas que são cobertos de pinturas e dourados sobre suporte de madeira; utilização de pedra de cor diferente; caiação do edifício ${ }^{20}$.

O que está aqui em jogo não é, portanto, a necessidade da intervenção -até porque o próprio Herculano informa que o monumento "arruinado em partes, carecia de reparos" "21- mas sim os moldes em que esta se processa.

15 Herculano, Alexandre: “A Arquitectura Gótica”, O Panorama, vol. I, n. ${ }^{\circ} 1$, 1837, pág. 2-3.

16 Herculano, Alexandre: "Os Monumentos I" in Opúsculos. vol. I. Lisboa: Presença, 1982, pág. 207, 1. ${ }^{\text {a }}$ ed. 1838.

17 Herculano, Alexandre: «Mais um brado a favor dos Monumentos I", in Opúsculos. vol. I. Lisboa: Presença, 1982, pág. 252, 1. ${ }^{\mathrm{a}}$ ed. 1839.

18 Mais concretamente escreve "os capiteis adornados de esculturas variadas e subtis".

19 Herculano, Alexandre: “Mais um brado...», pág. 207.

$20 \quad$ Ibidem, pág. 207.

21 Ibidem, pág. 207. 
E para Alexandre Herculano -para quem a valorização da arquitectura passa sobretudo pela sua carga simbólica e histórica-, o único caminho é o da preservação do "aspecto de veneranda antiguidade" ${ }^{22}$ do monumento, ideia que expressa precisamente a propósito de Nossa Senhora da Oliveira e que, mais imediatamente é destruída pelo tipo de intervenção ai realizada.

Importa aqui notar, que a preservação da imagem de antiguidade dos monumentos será talvez, simultaneamente a ideia e o objectivo mais fortemente enraizados no pensamento dos meios literários e políticos da época.

Aliás a já referida falta de formação e/ou sensibilidade para questōes de outra índole, fará da cal, dos dourados e das pinturas um dos principais objectos, mais repetidamente mencionados e aparentemente mais detestados das críticas provenientes dos meios literários, o que, se em parte se pode atribuir a uma sua muito provável generalização, por outro lado, faz pensar que talvez a principal razão assente no facto de se tratar precisamente das transformações que mais fácil e imediatamente se podem apreender.

Herculano - mais uma vez um bom exemplo- fala de «abobadas e colunas da emprestada alvura e de ridículos ouropeis" ${ }^{23}$, das "rugas caiadas e douradas" da Sé de Lisboa ${ }^{24}$, dos "vândalos do pau dourado e do estuque " ${ }^{25}$ e do seu desejo de "branquear e estragar" ${ }^{26}$.

Explica que "renovadores, caiadores, ou enlabuzadores de monumentos" são uma "espécie mestiça entre os homens de juízo e os mentecaptos do camartelo; espécie demente que luta entre o passado e o presente; espécie absurda que crê em Deus, e não na arte" ${ }^{27}$.

Da Colegiada de Guimarães, «hoje desaportuguesada e caiada e dourada e mutilada pelo mais bárbaro abuso da riqueza e da ignorância clerical $\gg^{28}$ nada mais vê a criticar ${ }^{29}$.

\footnotetext{
22 Ibidem, pág. 208.

23 Herculano, Alexandre: Cenas..., págs. 49-50.

24 Herculano, Alexandre: "Arras Por Foro de Espanha", in Lendas e Narrativas. vol. I. Lis. boa: Livraria Bertrand, 1980, pág. $76,1{ }^{\text {a ed. } 1841-42 .}$

25 Herculano, Alexandre: “Mais um brado...», pág. 208.

26 Ibidem, pág. 209.

27 Ibidem, pág. 206.

28 Herculano, Alexandre: “A Abóbada", in Lendas..., pág. 252, 1. a ed. 1839.

29 No texto revisto e acrescentado dos seus artigos do Panorama que, sob o título de Monumentos Pátrios, voltará a publicar já na década de 1870, Herculano nada altera a este respeito.
} 
No entanto, Vilhena Barbosa, que também lamenta a forma como "mascararam com estuques e doirados as suas venerandas feiçōes", conta que lhe rasgaram "as ogivas das naves em arcos mais elevados" ${ }^{30}$, ou seja, que se introduziram no edifício alterações estruturais de fundo a que Alexandre Herculano parece ter sido indiferente, talvez porque aquela elevação da nave correspondia a um reforço do carácter gótico do edifício, único aspecto que vê interesse em valorizar.

Mas, Nossa Senhora da Oliveira, é também um exemplo paradigmático da dualidade de atitudes em relação ao património existente na época e da frequente injustiça relativa das críticas no que se refere áqueles a quem eram dirigidas.

Ao contrário do que os textos de Herculano poderiam fazer supor, o edifício não foi radicalmente transformado pelos monges na década de 1830.

As descrições anteriores que dele existem, falam de uma construçāo que, à semelhança de tantas outras, foi crescendo e se foi metamorfoseando à medida das necessidades e do gosto do momento.

No seu conjunto, a Colegiada (Fig. 3) é composta por uma igreja reconstruída no séc. XIV a que, dois séculos mais tarde, foram acrescentados um claustro e uma torre, o que lhe garante, à partida, um carácter estruturalmente heterogéneo, reforçado pelo facto da cabeceira da igreja ter sido reconstruída no séc. XVII e remodelada e aumentada 100 anos depois.

Naturalmente, este percurso construtivo foi acompanhado de adaptaçōes ao gosto da época.

A igreja que parece ter sido objecto preferencial das intervenções "decorativas" é descrita, pelo menos desde os fins do séc. XVII, como sendo "toda azulejada e pintada" no interior, com a nave central abundantemente decorada com "painéis da vida da Nossa Senhora" ${ }^{31} e$

\footnotetext{
30 Archivo Pittoresco, vol. VI, n. 45, 1861, pág. 354. Note-se que a referência a esta alteraçāo é apenas referida por Vilhena Barbosa o que poderá levantar a possibilidade de que este se tenha enganado, sendo necessária uma investigação, que nãơ cabe na economia deste trabalho efectuar, para apurar dos trabalhos efectivamente realizados em Nossa Senhora da Oliveira bem como da sua rigorosa cronologia.

31 Manuscrito datado de 1692. Transcrito in AzEvedo, P. Torcato Peixoto de: Memórias ressuscitadas da antiga Guimarāes. Porto: s.n., 1845. O texto do manuscrito é reproduzido com algumas variações, minimas, de forma in CostA, A. Carvalho da: Corografia Portugueza, vol. I, 1706, pág. 3 e Colmenar, Juan Alvarez de: Annales d'Espagne et de Portugal. vol. III. Amesterdāo: s.n., 1741, pág. 239. Vd. as transcrições reunidas por Rosas, Lucia Cardoso: Monumentos Pátrios. A arquitectura religiosa medieval - património e restauro. (1835-1929). vol. II. Tese de Doutoramento. Universidade do Porto, 1995, pág. 199
} 


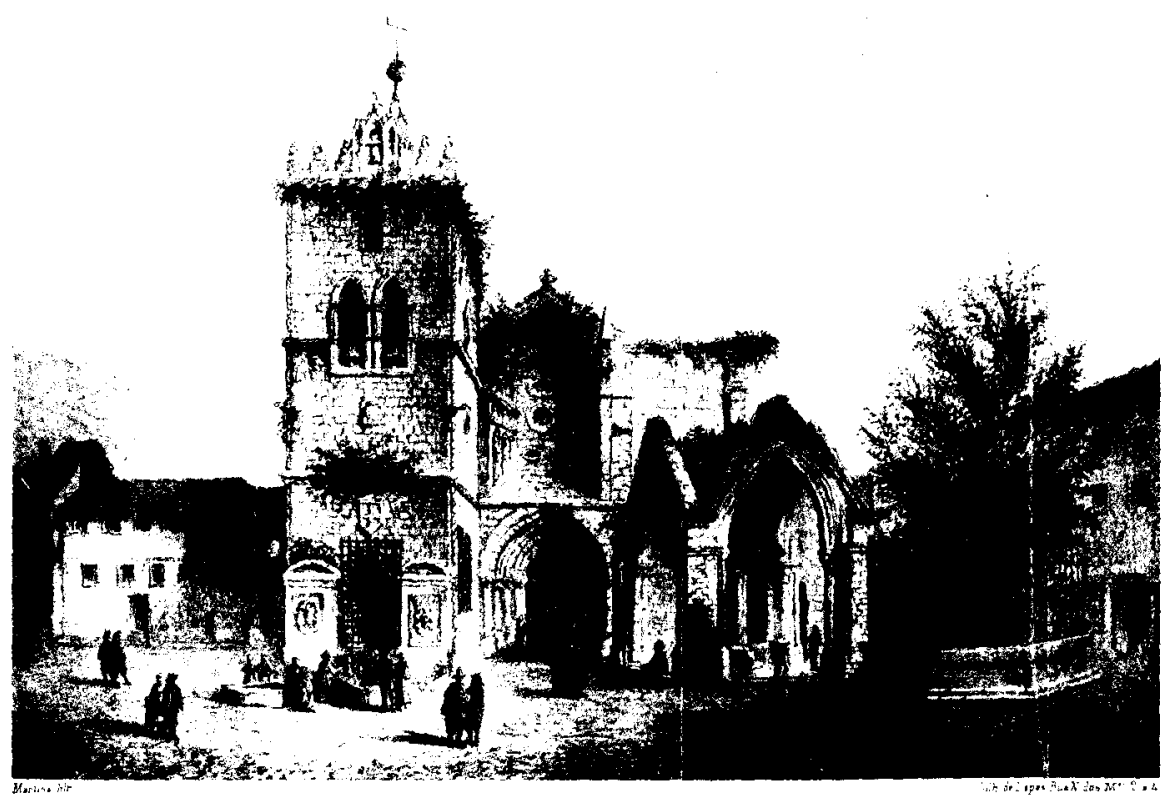

Fig. 3. Colegiada de Guimarães. Gravura publicada na Illustração Popular, n. $18,1866$.

todas as frestas cobertas por "vidraças muito claras com muitas imagens pintadas \& douradas" ${ }^{32} \mathrm{com}$ as armas de D. João I e D. Filipa de Lencastre.

Nesta ornamentação esfusiante -- $\mathrm{O}$ corpo da igreja [...] está coberto de azulejo quase por todo lado; \& nos intervalos, onde não existe azulejo, está pintado ou dourado" ${ }^{33}$ - a preferência parece ir para o azulejo, sendo a decoração "pintada \& dourada" relegada para as paredes "onde [este] se não pode assentar $"{ }^{34}$.

O efeito final parece ser do agrado de todos, com excepção do «bom espelho de vidraças» ${ }^{35}$ sobre a porta principai, «uma nobre janela, enriquecida com escultura" que Kinsey lamenta ter sido "emparedada, e de

32 Costa, A. Carvalho da: op. cit., pág. 3.

33 No original: "Le corps de l'Eglise [...] est azurée presque par-tout; \& dans les endroits, oú il n'y a pas d'azur, elle est peinte ou dorée" (COLMENAr, Juan Álvarez de: op. cit, pág. 239).

34 Costa, A. Carvalho da: op. cit., pág. 3.

35 Ibidem, pág. 3. 
novo construída por forma a incluir quatro pequenas janelas redondas» de "péssimo" resultado final ${ }^{36}$.

Quanto ao claustro, foi caiado e caiado se manteve pelo menos até 1876 , altura em que Vilhena Barbosa ${ }^{37}$ ainda refere as suas «muitas camadas de cal».

Face ao panorama atrás descrito constata-se que, em termos gerais, os principais aspectos criticados por Alexandre Herculano na Colegiada parecem existir pelo menos desde os fins do século XVII, data da primeira descrição atrás identificada.

Assim, se bem que o autor refira especificamente as obras que se faziam em Nossa Senhora da Oliveira «há sete ou oito anos" ${ }^{38}$, portanto desde 1831-32, e que estas eventualmente se tenham prolongado pelo menos até $1843^{39}$, nelas gastando o cabido "grossas somas» especialmente reunidas para o efeito ${ }^{40}$, o tom da intervenção bem como as principais alterações produzidas no edifício ser-Ihe-iam claramente anteriores.

A intervenção dos cónegos inscreve-se, portanto, num registo absolutamente coerente com a história do edifício, em relação ao qual actuam com inteiro à vontade de habitantes de longa data que apreciam a casa que herdaram tal como chegou até eles.

É neste sentido que a sua actuação deve ser entendida.

Gostando do edifício que têm, tal como ele se apresenta, fazem-lhe obras de recuperação no sentido de the devolver a frescura perdida, informadas por um gosto que, de resto, se pensa ser bastante generalizado na altura.

A indignação de Alexandre Herculano ${ }^{41} \mathrm{com}$ a reaç̧ão dos habitantes de Guimarães, que "louvaram o bonito da nova obra" é disso mesmo testemunho.

A persistência das críticas na imprensa a monumentos pintados, caiados e dourados, apenas vem confirmar a sua existência generalizada, que não se pode explicar sem uma idêntica generalização do gosto por eles.

\footnotetext{
36 No original: "a noble window, enriched with sculpture"; "walled up, and again performed to admite four small round windows" e "very bad" (KINSEY, William Morgan: Portugal Illustrated. London: 1829).

37 Barbosa, I. Vilhena: "Monumentos Religiosos do Minho II. A Colegiada de Nossa Senhora da Oliveira em Guimarães", Commercio do Porto, n. 71, 24-3-1876.

38 Herculano, Alexandre, "Mais um brado ...", pág. 207.

39 Barbosa, I. Vilhena: Archivo Pittoresco, vol. VI, n. ${ }^{\circ} 45,1861$, pág. 354.

40 Herculano, Alexandre: “Mais um brado...", pág. 207.

41 Ibidem, pág. 208.
} 
A valorização patrimonial da raiz medieval das construções, do gótico em particular no que a Herculano se refere, que informa as críticas, é a excepção e não a regra no que se refere ao conjunto da população.

No caso de Nossa Senhora da Oliveira, apenas um entre muitos, aquilo que mais fortemente ressalta do processo é a radical diferença de atitudes que, face a uma mesma peça, se constata existir entre a cultura erudita vigente personificada por Herculano e a cultura popular personificada pelo cabido e pela população de Guimarães em geral.

Para os primeiros, o interesse da construção assenta nas suas características originais, características que se quer ver preservadas ou mesmo reforçadas.

Para os segundos, o brilho do monumento advém-ihe das intervenções posteriores, aquelas com que se identificam e que realmente apreciam.

A saturação decorativa do espaço interior da igreja, que tanto desgosta Herculano porque contrária à severidade gótica, tal como a entende, é precisamente a maior qualidade que os vimaranenses nela encontram.

Isto não significa que não dêem igualmente importância ao valor de antiguidade do edifício, decorrente da construção de base que se dedicam a adornar, significa sim a inexistência de um quadro patrimonial estruturado, a inexistência de sentimento de distância em relação ao passado do qual, pelo contrário, cónegos e população se apropriam e com o qual parecem alegre e descuidadamente conviver.

Por seu lado, Herculano representa o entendimento do valor patrimonial do edifício num quadro relativamente estreito e purista.

Para ele, existe a forma original, no caso leia-se medieval, sendo tudo o mais condenável. O monumento é um documento, mas um documento de um momento ideal que se foi sujando ao longo do tempo. As metamorfoses que foi sofrendo não são história, são degradação.

Mais que um estilo, para Herculano o gótico corresponde à objectivação de um ideal religioso e político, o único que interessa, aquele que vale a pena preservar, aquele que é genuinamente nacional. Por isso fala de "desaportuguesamento" quando resume as alterações da Colegiada.

Outros há, como Garrett, para quem D. Manuel e os Descobrimentos têm a preferência, que encontram no manuelino e não no gótico a verdadeira expressão da nação e da arte nacional.

A frágil formação arquitectónica de quase todos baralha na prática as escolhas e a sua aplicação, mas para quase todos também as intervenções artísticas de setecentos são desastrosas. 
Retomando as palavras de Herculano, Mafra era já "uma sensaboria de mármore " ${ }^{42}$ mas a Basílica da Estrela é "uma caricatura de outra caricatura", a expressão de um gosto que infelizmente veio para durar, numa época em que tudo foi entregue "aos arquitectos e os arquitectos tudo estragaram ", caiando, dourando, enfeitando ${ }^{43}$.

Trata-se portanto de uma rejeição da gramática artística dos séculos anteriores, que se considera contaminante do património a preservar e, consequentemente, se deseja eliminar, sendo portanto, no quadro da definição patrimonial que radica a noção de "correcção" ou «incorrecção" das intervenções, mas se a escolha e valorização desse património resulta da combinação de factores diversos e de leitura complexa, o gosto ou desgosto pela cal e pelos dourados tão pouco é simples.

E é aqui que, talvez eruditos e populares se aproximem, na medida em que a apreciação de ambos passa também por uma questão de gosto.

No caso dos primeiros, de um gosto mais elaborado, assente numa muito particular leitura da história portuguesa combinada com pressupostos artísticos e com reflexos directos na escolha patrimonial, mas ainda assim uma questão de gosto.

No caso dos segundos, um gosto pela cor e pela cal com raízes ancestrais que, no caso em questão, surge perfeitamente enquadrado pela permanência de um gosto de pendor barroco profundamente enraizado e cuja sobrevivência mereceria um estudo mais alargado.

Na prática, no confronto entre estas duas sensibilidades se esgota em grande parte o problema da intervenção no património edificado, tal como surge à luz dos textos publicados em sua defesa na imprensa romântica portuguesa da primeira metade de oitocentos.

42 Herculano, Alexandre: "Duas Épocas e Dois Monumentos ou a Granja Real de Mafra" in Opúsculos. vol. II. Lisboa: Presença, 1983, pág. 140, 1. a ed. 1843.

43 Herculano, Alexandre: "Os Monumentos 1", pág. 185. 